\title{
Computing technologies for wellness
}

\author{
Cristina Manresa-Yee ${ }^{1} \cdot$ Ramon Mas $^{1}$
}

Published online: 17 August 2020

(c) Springer-Verlag GmbH Germany, part of Springer Nature 2020

Guest editors,

To move towards a healthy, mindful and fulfilled lifestyle, well-being dimensions such as the physical, psychological or social ones should be considered for all individuals, regardless of their capabilities.

Information and Communication Technologies (ICTs) have been introduced to nearly every aspect of our lives and the well-being sector is no different. ICTs can facilitate wellbeing by encouraging physical exercise, improving aspects like emphasizing the relations with others and the environment, allowing the person to participate in intellectual and cultural activities or recognizing awareness and acceptance of one's feelings.

This special section on Computing Technologies for Wellness contains a collection of four extended papers from INTERACCIÓN 2018 addressing this topic. INTERACCIÓN is an annual International Conference on Human-Computer Interaction (HCI) promoted by the Spanish Asociación para la Interacción Persona-Ordenador (AIPO), whose main aim is to promote and disseminate recent advances in the field of Human-Computer Interaction.

INTERACCIÓN 2018 was the 19th edition of the conference and took place on September 12-14, 2018 at the Universitat de les Illes Balears in Palma (Mallorca, Spain). The conference aimed at providing a forum, both for academia and industry, to exchange ideas and discuss the latest trends in interactive technology following a multidisciplinary approach. The conference program committee selected 29 regular papers and 16 short papers to be presented at the conference and published in the conference proceedings [1].

The four extended papers for this special section were selected from among all the accepted papers by the special issue guest editors Cristina Manresa-Yee and Ramon Mas, based on the relevance to the journal and the reviews of the conference version of the papers. The authors were asked

Cristina Manresa-Yee

cristina.manresa@uib.es

1 Palma, Spain to revise and significantly extend the conference paper for journal publication. The revised papers again went through the standard journal-style review process and are finally presented to the readers in the present form. We appreciate the willingness of the authors and the reviewers to help in organizing this Special Section.

The four extended papers in this special issue cover technologies to improve the well-being of peoples with ASD, methodologies and models considering accessibility and usability issues and an analysis of web adaptation techniques for people with low vision.

The first work by Quintal and Macías is entitled "Measuring and Improving the Quality of Development Processes Based on Usability and Accessibility". In this work, the authors introduce MODECUA, a capability maturity model which provides a framework to evaluate development processes centered on usability and accessibility.

Moreno, Valencia, Pérez et al. present "An exploratory study of web adaptation techniques for people with low vision". In this work, they explore and review navigation strategies of low-vision users to define adaptation techniques that optimize web interfaces.

In the work "Towards emotional interactive videogames for children with Autism Spectrum Disorder" by Baldassarri, Passerino, Ramis et al., the authors present two experiences using videogames to promote communication and attention in children with Autism Spectrum Disorder (ASD).

Finally, Peñeñory, Collazos, Bacca et al. present "APRehab: a methodology for serious games design oriented to psychomotor rehabilitation in children with hearing impairments", a work that describes a methodology to guide designers to develop serious games for rehabilitation addressed to hearing impaired children.

The works presented in this Special Section are a step forward in the design and development of interactive systems addressing well-being for all. We hope that the readers enjoy this special section and get inspiration and useful ideas and insights from the works included. 


\section{Reference}

1. Manresa-Yee, C., Mas Sansó, R. (eds.): Proceedings of the XIX International Conference on Human Computer Interaction, Interacción 2018, Palma, Spain, September 12-14, 2018. ACM, ISBN 978-1-4503-6491-1 (2018)
Publisher's Note Springer Nature remains neutral with regard to jurisdictional claims in published maps and institutional affiliations. 